\title{
Prevalence and Factors Responsible for Cohabitation among Undergraduates of Adekunle Ajasin University, Ondo State, Nigeria
}

\author{
Ojewola F.O., Akinduyo T.E.* \\ Department Guidance and Counselling, Adekunle Ajasin University, Akungba- Akoko, Ondo State, Nigeria \\ *Corresponding author: tosigno07@yahoo.com
}

\begin{abstract}
The study examined prevalence and factors responsible for cohabitation among undergraduates of Adekunle Ajasin University, Ondo State, Nigeria. The population for the study consisted of all the undergraduates of the university, four hundred and fifty (450) students were randomly selected from the six faculties. Prevalence and Factors of Cohabitation among Undergraduates Questionnaire (PFCUQ) was the instrument administered for the study. One research question was raised and three hypotheses were generated based on variables of age, gender and religious affiliation. The findings showed that the first and third hypotheses indicated no significant difference in cohabitation on the basis of age and faculties. Whereas, the second hypothesis indicated that significant difference existed on the basis of religious affiliation. The study therefore recommended that counselling should be given on regular basis to students on the need for good moral and chaste living. Parents, University authority and religious bodies should try to alleviate the problem of cohabitation by providing suitable, conducive and affordable accommodation within the University environment.
\end{abstract}

Keywords: prevalence, cohabitation, undergraduates, gender, age and faculties

Cite This Article: Ojewola F.O., and Akinduyo T.E., "Prevalence and Factors Responsible for Cohabitation among Undergraduates of Adekunle Ajasin University, Ondo State, Nigeria.” American Journal of Educational Research, vol. 5, no. 6 (2017): 650-654. doi: 10.12691/education-5-6-10.

\section{Background to the Study}

Cohabitation among students has now become very rampant in most institutions of higher learning. The nonresidential accommodation in many higher institutions tend to encourage this new trend of students cohabiting, unlike what was in operation in the olden times. Initially all students were accommodated within institution's halls of residence. Those students accommodated within institution's hall had rules and regulation guiding their stay. Thus within a short time, Nigerian tertiary institutions began to experience challenge of inadequate hostel accommodation [5], because the population of students continues to grow without corresponding growth in the number of halls of residence and other physical facilities. Therefore, cohabitation became the order of the day among the students in higher institutions of learning. Cohabitation is an act of a man and woman living together and sometimes sharing marital intimacy without being legally married [17]. Alo [3] asserted that premarital cohabitation has become a common phenomenon among Nigerian University Undergraduates.

Cohabitation among individuals of opposite sex is a predisposing factor to the initiation of sexual activities [15]. Cohabitation results in two independent people almost like room-mate, who are sexually involved, instead of being committed to one another for the rest of their lives [18]. Students who should to be engaged in serious academic pursuit often end up performing below expectation because of all these distractions. Martin, Martin and Martin [13] corroborated this idea that the number of young adults engaging in premarital sexual behavior has increased to 60 percent in the last 20years. The World Health Organizations [20] equally observed that premarital sexual activities among young adults are high and increasing in Africa with the inclusion of Nigeria. Cohabiting students will often engage in unprotected sex which could result in sexually transmitted infections and the much dreaded HIV/ AIDS diseases [16]. According to Arisukwu [6], cohabitation has serious health effect on the female students who may indulge in the use of oral contraceptive in order to avoid unwanted pregnancy which may truncate their educational aspirations. Should pregnancy occur, such female students are more likely to seek abortion as an alternative [6]. This has serious health challenges for such students who may visit quack doctors and medical practitioners without adequate experiences and qualifications [14]. Some may frown at abortion and thus give birth to unwanted babies who may not be properly catered for by these students.

Cohabitation among university students has led to moral decadence in the society. According to the AAUA Vice Chancellor (2015), living together and having sexual relationship without being married is a trend that has 
virtually eroded the level of morality among youth, particularly students of higher institutions. It has been observed that many of these students cohabiting do not necessarily get to the level of marriage after all. Many of such relationship often end abruptly. Rena [18] confirmed that couples who cohabit before marriage have a 50 percent high divorce rate than those who do not. Ogunsola [16] in his research findings on premarital behaviours as determinant of marital stability observed that premarital cohabitations has no positive effect on marital stability of the couples in Oyo state, Nigeria. Cohabitation is totally against the norms and values of African society. Allowing young unmarried couple live together especially where they do not have family affinity is often regarded as an albatross [6]. Whereas, some students cohabit without allowing their parents to know about it, some parents are the ones encouraging their children to do so due to their inability to meet their basic needs. Many of these students are exposed to risk and harm as they cohabit. Students who cohabit are vulnerable and susceptible to attack and abuse by both outsiders and even their partners. Formerly, the culture of premarital sexual behaviours used to be a taboo in Nigeria [3]. Unfortunately however, the contemporary youths have abandoned this valued tradition for inglorious culture of premarital sexual activities [1].

Age is an important factor that could influence cohabitation among university students. Now, there are many students that entered the university being very young, hence many of them are naive. This is buttressed by the findings of Ogunbamila [15] that indicated that early young adults were mostly prone to premarital sexual behaviours. Cohabitation is common among undergraduates because many of them are being free for the first time; hence, they tend to enjoy the freedom, independence and are less monitored by either their parents or guardians. Alo and Akinde [4] stated that cohabitation and sexual behaiours are more common with them, since their age range falls between 15 - 24 years. Adeoye et al [1] in their study on premarital sexual behaviours among undergraduates in Nigerian universities found the age categories of 14 -15 years and 19 - 25 years to have experienced premarital sexual behaviour at the same level. Thus, age did not have significant influence on youths' sexual behaviours. Martin, Martin and Martin [13] found that individuals within the ages of 15 - 17 years were more involved in premarital sexual behaviours than those in the late young adulthood.

The issue of religion is equally an important variable in cohabitation among undergraduates. Studies indicated that those with religious affiliations are less likely to cohabit than those without religious affiliations [10,19]. Gault-Sherman and Draper [9] equally observed that individual religiosity is positively associated with more traditional family attitudes and behaviour. They further stated that norms regarding family formation, behaviour of individual are commonly shaped and reinforced by religious institutions. It is further noted that strong religious parents can affect their child's behaviour through guidance and supervision. Regardless of the child's value on cohabitation, the child may decide not to cohabit in order to avoid embarrassing his/her parents, thus, prevent causing them negative social sanctions or instigating family conflict [9]. It seems there is a decline in religious authority and there are dramatic changes in religious structures $[8,11,12]$. Religious inclination notwithstanding, contemporary adolescents tend to do what they desire without any serious consideration for their religious beliefs.

\subsection{Statement of Problem}

Cohabitation among undergraduates has become a contemporary issue plaguing many higher institutions of learning. Many students tend to lose sight of why they are in school and are preoccupied with the unessential issues. This tends to course lots of distraction for many students. The purpose why they are in school is forgotten to other responsibilities not related to learning .This tend to make many students to perform below expectations, since often times these students are never in the school/class for any serious academic work. Alo and Akinde [4] observed that cohabitation and sexual behaviours are more common with these youths.

The culture of chastity and purity is no longer promoted and encouraged among these youths. Admission to higher institution is considered liberty and freedom to do whatever they like. Cohabitation has become so rampant that some youths have become promiscuous, changing boyfriend /girlfriends regularly. This has turned many ladies to street girls and prostitutes. AAUA VC [2] asserted that cohabitation among unmarried students has been on the rise and if deliberate and pragmatic steps are not taken by all stakeholders including management of tertiary institutions, parents and religious leaders, this anomaly will continue to rise unabated and the society will ultimately suffer for it. This is a serious call, hence something drastic must be done to stop this menace which is threatening the survival of our youths in higher institutions.

Although some work have been done by Bello and Ogunsanwo [7] on psychological consequences of cohabitation among Tai Solarin University of Education, Ogun State, Nigeria, [6] researched on cohabitation among University of Ibadan undergraduate students. Ogungbamila [15] worked on demographic predictors of premarital sexual behaviours among undergraduates. Despite all these research efforts the incidence of cohabitation still persist among students in higher institutions especially students in Adekunle Ajasin University. Hence these researchers are interested in assessing the prevalence and factors responsible for cohabitation among AAUA students. One research question and three hypotheses were formulated to guide the study.

\subsection{Research Question}

1. What is the prevalence of cohabitation among the university students?

\subsection{Research Hypotheses}

1) There is no significant difference in cohabitation on the basis of age among undergraduates in the university.

2) There is no significant difference in cohabitation on the basis of religious affiliation among undergraduates in the university. 
3) There is no significant difference in cohabitation on the basis of faculty among undergraduates in the university.

\section{Methodology}

The research design adopted for this study is descriptive survey. The population for the study includes all the university undergraduates of Adekunle Ajasin University, Ondo State, Nigeria. The sample comprised four hundred and fifty students (450) randomly stratified from six faculties in the University. This involves random selection of male and female students from each of the six faculties. A questionnaire titled Prevalence and Factors of Cohabitation among Undergraduates Questionnaire (PFCUQ) was constructed by the researchers. The questionnaire was constructed using items from reviewed literature. Twenty items were used to elicit response from the respondents. Four points Likert-type scale format of strongly agreed, agreed, disagreed and strongly disagreed were used to elicit response from the respondents. To ascertain the validity and reliability of the instruments it was given to experts in the departments of Guidance and Counselling and Test and Measurement. Suggestions were made and correction effected to enhance the efficiency and usability of the instrument. The reliability of 0.76 was obtained using Pearson Product Moment Correlation Coefficient procedure. The questionnaire was administered by the researchers and other co-opted research assistants to the undergraduates. The students were administered with the questionnaire and it was retrieved immediately. The data was analysed using t-test, ANOVAL and Post HOC tests.

\section{Result}

The result on Table 1 indicate item by item analysis of rank orders on the prevalence of cohabitation among AAUA undergraduates items, 6,1,12,20,4 and 2 were ranked $1^{\text {st }}-6^{\text {th }}$ positions respectively. Item 6 has the highest mean of 3.03 which stated that cohabitating is the best means to select mates. The last in the serial number is item 2 which had the mean of 2.77 which stated that peer influence encourages cohabitation.

Hypothesis 1 - There is no significant difference between cohabitation on the basis of age among undergraduates in the university.

The result on Table 2 shows ANOVA results on the basis of age. The $f$ calculated ratio of 2.26 was found to be less than critical $f$ ratio of 3.09. Thus, the null hypothesis of no significant difference was accepted on the basis of age among undergraduates. Hence age does not have effect on cohabitation among students. This indicate that cohabitation is not affected by any age range.

Hypothesis 2: There is no significant difference in cohabitation on the basis of religious affiliation among undergraduates in the University.

Table 3 shows that the calculated f-ratio is 7.506, while the critical $\mathrm{f}$ ratio is 3.09 . Since the calculated $\mathrm{f}$ ratios is greater than the critical $\mathrm{f}$ ratio, the hypothesis is rejected. This means that there is a significant difference on the basis of religious affiliation on cohabitation among AAUA students. Since there is a significant difference on the basis of religious affiliation on cohabitation using Analysis of Variance (ANOVA), Duncan Multiple Range Test (DMRT) was used as a post - hoc test to determine the religion that was responsible for the significant difference.

Table 1. Mean and rank order of prevalence of cohabitation among University undergraduates

\begin{tabular}{|c|l|c|c|}
\hline S/N & Items & Mean & Rank \\
\hline 06 & Cohabiting is the best means to select mates. & 3.03 & $1^{\text {st }}$ \\
\hline 01 & Many students cohabited due to financial constraint & 3.02 & $2^{\text {nd }}$ \\
\hline 12 & Cohabitation highly recognized by fellow students & 3.01 & $3^{\text {rd }}$ \\
\hline 20 & Desire for intimacy and sex on regular basis is the reason for cohabitation & 2.91 & $4^{\text {th }}$ \\
\hline 04 & Lack of conducive hostel facilities tend to promote cohabitation & 2.87 & $5^{\text {th }}$ \\
\hline 02 & Peer influence encourages cohabitation & 2.77 & $6^{\text {th }}$ \\
\hline
\end{tabular}

Table 2. ANOVA showing difference on the basis of age among undergraduates of AAUA

\begin{tabular}{|l|c|c|c|c|c|}
\hline Sources of Variance & Sum of Square & df & Mean Square & Cal f & Critical f \\
\hline Between Groups & 128.690 & 2 & 64.345 & 2.226 & 3.09 \\
\hline Within Groups & 12922.501 & 447 & 28.909 & & \\
\hline Total & 13051.191 & 449 & & & \\
\hline
\end{tabular}

NS= Not Significant at 0.05 alpha level.

Table 3. ANOVA showing difference on the basis of religious affiliation among undergraduates of AAUA

\begin{tabular}{|l|c|c|c|c|c|}
\hline Sources of Variance & Sum of Square & df & Mean Square & Cal f & Critical f \\
\hline Between Groups & 424.095 & 2 & 212.049 & 7.506 & 3.09 \\
\hline Within Groups & 12627.096 & 447 & 28.249 & & \\
\hline Total & 13051.191 & 449 & & & \\
\hline
\end{tabular}

$*=\mathrm{P}<0.05$ 
Table 4. Duncan Multiple Range Test (DMRT) showing difference in cohabitation on the basis of religious affiliation among undergraduates

\begin{tabular}{|c|c|c|c|}
\hline Duncan & Grouping & Mean N & Religious Affiliation \\
\hline A & 25.322 & 298 & Christianity. \\
\hline B & 23.928 & 97 & Islam African \\
\hline C & 22.565 & 55 & Traditional religion \\
\hline
\end{tabular}

Note: Means having the same letters are not significantly difference.

Table 5.

\begin{tabular}{|c|c|c|c|c|c|}
\hline Source of Variance & Sum of Square & df & Mean Square & Calf & Critical $\mathrm{f}$ \\
\hline Between Groups & 199.966 & 4 & 49.992 & 1.731 & 2.46 \\
\hline Within Groups & 12851.225 & 445 & 28.879 & & \\
\hline Total & 13051.191 & 449 & & & \\
\hline
\end{tabular}

Table 4, the Duncan Multiple Range Test (DMRT) result was used to determine which religious affiliation mean led to the significant difference that was noted in the ANOVA result of Table 3. The DMRT results indicated Christianity with the mean score of 25.322 differed from group 2 Islam and group 3 African traditional religion with mean scores of 23.928 and 22.564 respectively. Thus the significant difference noted in the ANOVA results in Table 2 was due to the fact that the means in the three groups differed significantly from each other.

Hypothesis 3: There is no significant difference in cohabitation on the basis of faculty among undergraduates in the AAUA.

Table 5 shows that the calculated f- ratio of 1.731 while critical $f$ ratio of 2.46 is more than the calculated value since the calculated $f$ ratio is less than the critical $f$ ratio than the null hypothesis is accepted. This means that there is no significant difference in cohabitation among undergraduates on the basis of faculty in AAUA.

\section{Discussion}

The result of the first research hypothesis showed that there was no significant difference in cohabitation on the basis of age among undergraduates in AAUA. The null hypothesis of no significant difference was accepted on the basis of age. In the studies by Ogungbamila [15] it was found that early young adults were more prone to premarital sexual behaviours .The result is also inconsonance with the findings of Alo\& Akinde [4] that cohabitation and sexual behaviours are more common with those within the age range of $15-24$ years. This probably collaborate the result of this finding that cohabitation is not limited to any age range among undergraduates of AAUA.

The result of the second research hypothesis showed that there was significant difference in cohabitation on the basis of religious affiliation among undergraduates. This is supported by the findings of Katz, [10]; Stanley, Whitton \& Markman, [19], that those with religious affiliation are less likely to cohabit than those without religious affiliations. This is equally supported by Gault \& Draper [9] that stated that individual religiosity is positively associated with more traditional family attitudes and behaviour. They further noted that strong religious parents can affect their child's behaviour through guidance and supervision. Regardless of the child's value on cohabitation, the child may decide not to cohabit in order to avoid embarrassing his /her parents. This probably influenced the outcome of the result obtained which indicated that there was significant difference in cohabitation on the basis of religious affiliation. Although this is contrary to the findings of Dempsey \& Devaus, [8]; Le Bourdais \& Lapierre- Adamcyk, [12]; Lplante, [11] that observed that there is a decline in religious authority and there are dramatic changes in religious structures.

The result of the third hypothesis showed that there was no significant difference in cohabitation among undergraduates on the basis of the faculty in AAUA. This means that the students in the different faculties do cohabitate at the same level. Hence cohabitation is not seen as any serious issue among undergraduates in AAUA. This is also in line with the assertion of Alo \& Akinde, [4] that cohabitation and sexual behaviours are more common with them. Alo [3] also found that premarital cohabitation has become a common phenomenon among the Nigerian University undergraduates. No wonder the result tinted to support the issue of cohabitation among the undergraduates in AAUA.

\section{Implication for Counselling}

The issue of cohabitation among university undergraduates has now become a serious issue that must not be handled with levity because this tends to have a multiplier effect on other facets of their lives. This kind of act leads to poor performance of some students while some drop out of school completely. A student that becomes pregnant may not be able to complete her education, if the parents are not supportive. Some may contact sexually transmitted diseases or infections. The issue of HIV \&AIDS is not far from such students. Thus all hands must be on deck, the parents, University authorities, religious bodies must be able to speak against this new trends of cohabiting among undergraduates.

Parents \&guardians must not only send their children and wards to school, they must visit them to know how and what they are doing in school. Some students cohabit without the knowledge of their parents because they are sure that their parents would never come to visit them in 
school. Some cohabit due to ignorance and inexperience, the desire to explore, and the sudden freedom is what prompt many of these students to misbehave. Adequate counseling and a good orientation programme will help many of these innocent students find their bearing not to misbehave and be misdirected.

The University authority should provide more hostel accommodation for the students especially the female students. The hostel accommodation provided by the university should be conducive and affordable for all the student. The school authority should monitor students living off campus to curb their excessive behaviour especially regarding cohabitation. The University authority could collaborate with the community leaders to curb the incidence of cohabitation among the university students. Students should be able to visit counsellors when facing challenges of cohabitation.

\section{References}

[1] Adeoye, A.O., Ola, O., \& Aliu, B. (2012). Prevalence of premarital sex and factors influencing it among students in a private tertiary institution in Nigeria. International of Psychology and Counselling, 4(1), 6-9.

[2] Ajibefu, I (2015, Sept, 10). AAUA, VC Condemns cohabitation among students. The Nation.

[3] Alo, A.O. (2008). Socioeconomics determinant of unintended pregnancies among Yoruba women of southwest Nigeria. International Journal of Sustainable Development 1 (4), 145-154.

[4] Alo, O.A. \& Akinde, I.S. (2010). Premarital sexual activities in an urban Society of South -West, Nigeria. English Australian Journal 2 (1), 1-16.

[5] Aluko, O.E. (2011). The assessment of housing situation among students in the University of Lagos. Africa research Review- An international Multi-Disciplinary Journal5 (3), 104-118.

[6] Arisukwu, O.C. (2013). Cohabitation among university of Ibadan undergraduate students .Research on Humanities and Social Sciences 3(5), 185-192.
[7] Bello, M.O. \& Ogunsanwo, B.A. (2013). The psychological consequence of cohabitation among students of Tai Solarin University of Education, Ijagun, Ogun State. Ozean Journal of Applied Sciences 6 (2) 1-6.

[8] Dempsey, K. \& Devaus, D. (2004). Who cohabit in 2001? The significance of age, gender, religion and ethnicity. Journal of Sociology 40:157-178.

[9] Gault -Sherman, M. \& Draper, S. (2012). What will the neighbors think? The effect of moral communities on cohabitation. Review of Religious Research 54(1) 45-67

[10] Katz, R. (2001). Effects of migration, ethnicity and religiosity on cohabitation. Journal of Comparative Family Studies 32: 587-599.

[11] Laplante, B. (2006). The rise of cohabitation in Quebec: Power of religion and power over religion. Canadian Journal of Sociology 31: 1-24.

[12] LeBourdais, C. \& Lapierre- Adamcy K, E. (2004). Change in conjugal life in Canada: is cohabitation progressively replacing marriage? Journal of Marriage and Family 66: 929-942.

[13] Martin, P., Martin, D. \& Martin, M. (2001). Young adult premarital sexual activity, cohabitation and attitudes towards marriage. Adolescence36, 601-609.

[14] Ofoegbu, C.I. (2002). Human development, family behaviour parenting, marriage and counselling Skills. Enugu: Snapp Press Ltd.

[15] Ogungbamila, A. (2013). Demographic predictors of premarital sexual behaviours among undergraduates .Nigerian Journal of Applied Behavioural Sciences 1, 68-74.

[16] Ogunsola, M.O. (2004). Premarital behaviour and length of courtship as determinant of marital stability among couples in Oyo State, Nigeria. Unpublished M.Ed project University of Ibadan, Ibadan.

[17] Ogunsola, M.O. (2011). The effect of premarital cohabitation on quality of relationship and marital stability of married people in Southwest, Nigeria. African Nebula, Issue 3, 16-24.

[18] Rena, R. (2006). Premarital sex-lessons from American experience, Ilorin (Nigeria). The Nigerian Journal of Guidance \& Counselling 11 (1), 134-155.

[19] Stanley, S.M., Whitton, S.W. \& Markman, H.J. (2004). May be I do: Interpersonal commitment and premarital or non-marital cohabitation? Journal of family Issues 25:496-519.

[20] World Health Organization. (2001). Sexual relations among young people in developing countries: Evidence from WHO case studies. Geneva: WHO. 